\title{
Chronic Traumatic Encephalopathy and the Built Environment
}

Dak Kopec, Kendall Marsh

University of Nevada,

Las Vegas

USA

\begin{abstract}
Traumatic Brain Injuries (TBIs) are often connected to the development of Chronic Traumatic Encephalopathy (CTE), a degenerative brain disease commonly found in athletes, military veterans, and others that have a history of repetitive brain trauma. This formative exploratory study looked at person-centred design techniques for a person with CTE. The person-centred design method used for this study was based on a two-tiered reductionist approach; the first tier was to identify common symptoms and concerns associated with CTE from the literature. This information provided specific symptoms that were addressed through brainstorming ideations. Each singular ideation accommodated the singular, or small cluster of symptoms, that affected a person with CTE in a residential environment. This method of understanding a health condition through its symptoms, and then designing for those symptoms can extend the practice of interior design by providing probable solutions to specific health symptoms, thereby including designers into the healthcare team. Commonly identified behavioural and physical symptoms of CTE served as the factors of analysis and thus a variable of design. The health condition symptoms became the variables of design, and each symptom was assessed through additional data obtained from the literature for environmental causality, mitigation, or accommodation. Once the outcomes were determined, each design implication was assessed for its relationship to specific design actions.
\end{abstract}

Keywords: person-centred design, Traumatic Brain Injuries (TBIs), Chronic Traumatic Encephalopathy (CTE), residential design 


\section{Introduction}

The purpose of this exploratory study was to develop a prototype design of a home that could address common symptoms that affect people with Chronic Traumatic Encephalopathy (CTE). The development of designs for individuals affected by specific health conditions has long been performed by clinical practitioners who lack design experience. Additionally, the use of design within the prevention, rehabilitation, and accommodation process has been undervalued. This means that the current literature pertaining to person-centred design initiatives for people affected by CTE is limited. Further compromising the study is that CTE continues to lack clear and decisive diagnostic criteria (Smith et al., 2019). What is known is that CTE is a neural degenerative disease that affects behaviours and behavioural responses (Turner et al., 2016). Exaggerated emotions related to anger, depression, and resentment are common mood disorders associated with CTE (Vynorius, Paquin, \& Seichepine, 2016; Turner et al., 2016).

According to the National Institutes of Health (2017), a primary goal for an ageing population with a health condition is to support their ability to remain in the home for as long as possible. Significant strides have been made in response to the American's with Disabilities Act, universal design, aging in place design, and more recently human and person-centred design. Each of these initiatives has the goal of providing adaptive designs that promote health, safety, and welfare for people affected by a health condition, and to support family members of the affected person to perform activities of daily living. A fundamental tenet of person-centred design is the elimination of environmental elements that could evoke reciprocal determinism. This places an added burden on the design to accommodate the person and their family with supportive elements without placing undue attention to a special need.

This study looked at person-centred design techniques for a person with CTE to accommodate the unique situations and circumstances encountered within the home environment. This study was based on the specific needs of a person with CTE and did not consider the needs of caregivers or others with whom the affected person cohabitates. The person-centred design method used for this study was based on a two-tiered reductionist approach. This approach allowed researchers to identify specific symptoms, solutions to each symptom, and then to aggregate the solutions into a single design motif. The approach to design solutions follows the tenets of synthetic logical positivism which is based on generalizations rooted from what is believed to be correct (Harvey, 2012). 
The first tier was to identify common symptoms and concerns associated with CTE from the literature. From the symptoms, the relationship between the designed environment and the symptom was identified. The relationships were then explored through a design thinking methodology based on brainstorming exercises. Interventions for specific symptoms based in design were then identified. Each of the identified probable design solutions was aggregated into segmented design schemes based on specific spaces within a home, and then assessed for relationships that would support a singular design style. The overarching design goal was to develop a singular design scheme that coincides with normative standards of a residential property, and devoid of overt elements that serve as symbols to signify the presence of a person with a differing ability or health-compromising condition.

\section{Understanding CTE Symptoms and Implications}

\section{Traumatic Brain Injury}

Traumatic Brain Injuries (TBIs) are grouped according to severity: mild, moderate, and severe (Blennow et al., 2016). According to Healthline, there are six different TBIs (Reed-Guy, 2018): (1) hematoma is an accumulation of blood outside the blood vessels that leads to increased pressure inside the skull; (2) hemorrhage is bleeding in the space around the brain, which causes pressure to build up inside the skull; (3) concussion is a sudden impact to the head causing the brain to collide with the skull; (4) edema is swelling of the brain from injury or virus resulting in pressure build-up inside the skull; (5) skull fracture occurs when the hard bone of the skull has been broken which is likely to be accompanied by damage to the brain; and (6) diffuse axonal injury is damage to the brain cells resulting in compromises to the brain's neurons. Mild TBI is the least severe of the different categories of brain injury. Blennow et al. (2016) state that a mild TBI is synonymous with a concussion that leads to the stretching and tearing of axons. These damaged axons thus lead to diffuse axonal injury.

TBls are a precursor to CTE and can result from a single profound injury, or from repeated trauma that causes progressive changes in neuropathways. Repeat injury from one of the above listed TBls, or from multiple TBIs from any assorted arrangement of the six types, can lead the development of CTE. The incidences of TBIs among traditional contact sports such as United States' football, boxing, and hockey are not believed to have increased over the years. However, identification and reports of TBls are better recorded. Additionally, 
there has been a rise in activities that can cause a TBI. The American Academy of Orthopedic Surgeons (2014) reported that head and neck injuries from sports such as skateboarding and snowboarding have been on the rise. The American Speech, Language, and Hearing Association states that visits to the emergency departments for a TBI rose by $70 \%$ between the years of 2001 to 2010 . Better reporting and increased types of sports resulting in TBls are just two factors contributing to the increased incidences.

Another group of people who often receive TBls are military personnel, miners, and other professions that use explosives. This population has seen increased incidents of TBls due to the advent of stronger blasting power. There has also been an increase in firearmrelated TBIs (Deng et al., 2019). Military personnel, avid hunters, and those engage in target practice are subjected to shock waves that cause the brain to bounce within the skull. The bouncing causes diffuse axonal injury, and hematomas from colliding with the skull. Blast-induced TBls have become the most dominant injury associated with the conflicts in Iraq and Afghanistan (Risdall \& Menon, 2011).

The third group of people affected by TBls are those who have received a single profound blow to the head. This might happen by the head coming in sudden contact with the pavement from a bicycle or motorcycle accident, or from an automobile accident. About sixty-nine million cases of TBIs are attributed to automobile accidents each year (Dewan et al., 2018), and overall one-third of all traumatic brain injuries (TBIs) can be attributed to falls with more than half occurring within the elderly population (Filer \& Harris, 2015). The injury could result in a concussion or any one of the six types of TBI listed above.

\section{Chronic Traumatic Encephalopathy}

Chronic Traumatic Encephalopathy (CTE) was formally known as Dementia Pugilistica or punch drunk because the condition was first identified in boxers, and the symptoms resembled intoxication (Zetterberg et al., 2019). Dementia Pugilistica suggests a relationship between CTE and other dementias such as Alzheimer's disease. However, the physiology of the two health conditions is limited to the presence of Tau pathology. Meaning that Tau tangles are found within the brains of people who have been affected by CTE and one or more forms of dementia. Hence, most experts agree that CTE and dementia are distinct entities that result in different behaviours (Turner et al., 2016). CTE can be a comorbid factor of dementia, most 
notably Alzheimer's disease, within people of advanced age (McKee et al., 2015). Because older people are susceptible to falls which can cause a TBI, fall prevention is an important step to limit the onset of CTE within older people. When dementia is mixed with CTE, the CTE health condition is likely to accelerate (McKee et al., 2015).

Not all TBls will result in CTE. Those most likely to develop CTE are those who receive multiple smaller TBls over time such as people who engage in contact sports, use dynamite or other explosives as part of their jobs (McKee et al., 2015), or perform stunts. The rise in the degree of competitiveness within sports, the increases in the explosive power of bombs and dynamite (Dewan et al., 2018), and proliferation of firearms have led many to consider CTE a silent epidemic. However, the diagnostic criteria for CTE have not yet been solidified, which means that the condition may or may not be over or under-diagnosed (Smith et al., 2019). The only sure way to determine if a person has CTE is an autopsy after death.

While no one is completely sure why CTE occurs in one person and not another, current evidence suggests that the damage to brain cells from diffuse axonal injury, often associated with concussions, cause the development of Tau tangles in those who are genetically susceptible. These Tau tangles impede neurosynaptic activity thereby facilitating neural atrophy. Like a person affected by Alzheimer's disease, the person affected with CTE will experience a loss of brain mass and density as the disease persists.

Symptoms of CTE include behavioural and mood changes, memory loss, cognitive impairment, and declined visual-spatial awareness (McKee et al., 2015). According to the Concussion Legacy Foundation, early symptoms of CTE can present during a person's late 20 s or 30 s, and progress from a mood and behavioural disorder to a decline in thinking and memory during the person's 40s or 50s. People with early symptoms of CTE will start to exhibit a decline in memory and will have trouble with planning, organisation, and multi-tasking. They also exhibit poor judgment, lack of impulse control, and develop paranoia which can lead to substance abuse, aggression, and suicide. Many of these symptoms are accompanied by apathy, depression, and unfettered rage (Patel et al., 2013).

\section{Symptoms and implications}

Identified symptoms were assessed in their singularity and further explored in terms of their relationships to the designed environment. These identified symptoms include headaches, 
visual-spatial difficulties, losses of attention and concentration, the decline of executive functions, irritability, impulsivity, aggression and explosivity, paranoia, short term memory loss, depression, and suicidality. Of these symptoms, there is much research pertaining to the causes of headaches from the environment and visualspatial disorientation that derive from optical illusions experienced by aviators. However, the everyday relationships between environmental factors used to assist in the relationship between headaches and visual-spatial difficulties are limited.

Friedman and De Ver Dye (2009) state that headaches can be caused by bright lights, the flickering of light, a cacophony of sounds, certain smells, and changes in weather. Controlling natural light infiltration through frosted glazing, and the use of drapery or blinds, are ways to control the levels of sunlight penetration into the home. The use of shade trees, awnings, and screen walls are the measures to control sunlight penetration from outside the home. Other design initiatives to complement these endeavours include the use of more saturated colours in combination (Deziel, 2018) with textured upholstery. At the very minimum, interior surfaces should limit reflectivity, which emulates light flicker. Gloss finished tile, high gloss paint, and polished stone are all examples of finish materials with high reflectivity. Similarly, headaches could arise from the brain working harder to process and make sense of optical illusions.

Visual-spatial difficulties arising from optical illusions where the perception of images are interpreted incorrectly, and disorientation results from the difference between expectation and reality i.e. one expects to place a plate on a counter only to put the plate on a portion of the counter resulting in the plate falling to the ground (Sánchez-Tena et al., 2018). The decline in visual-spatial awareness results either from the peripheral visual systems not working properly because of the health condition, or the data conveyed from the visual peripheral system not accurately processed by the brain. Illusions are created by the juxtaposition of color, the way light interacts with the object, and the textures used for material items. When developing a design for a person with visual-spatial difficulties, the designer must be aware of the principles of colour, light, and texture to avoid the accidental creation of an optical illusion.

The ability to use one's executive function to focus and concentrate on incoming sensory stimuli are personal abilities that aid in the performance of daily living activities. The use of design features to aid in the performance of these tasks has not been studied beyond 
access to views of nature. Kaplan and Kaplan (1989) developed the Attention Restoration Theory, which contends that humans use directed attention when focusing or concentrating, and performing tasks involving mental procedures or strategies. Kaplan and Kaplan assert that after a period of directed attention, people require activities based on undirected attention. The theory is based on interactions with the natural environment as the means to engage in undirected attention. Since the theory was published, much research has documented the benefits of access to nature (Ohly et al., 2016; Li \& Sullivan, 2016; Taylor \& Kuo, 2011).

The loss of memory may be enhanced using theta neurofeedback training (Reiner, Rozengurt, \& Barnea, 2014). Tapping into theta waves has long been the goal of hypnosis because of the increased suggestibility (Williams \& Gruzelier, 2001). The ability to bring about a theta state requires the ability to relax to the point just before sleep. Spaces designed to enhance this ability contain surfaces that contain organic or curvilinear shapes. Because rectilinear shapes have been shown to activate the parahippocampus thereby drawing attention to a specific area as opposed to focusing on nothing. Similarly, the addition of slow rhythmic repetitive sounds and limiting exterior sounds can help to evoke a theta state.

The use of environmental design to address the onset or mitigation of behaviours related to irritability, impulsivity, aggression and explosivity, paranoia, depression and suicidality has not been studied beyond the use of accessory objects used as projectiles. This is not to say that work based on the design of select spaces referred to by a host of different names that include calm-down, sensory, calming, de-escalation, and re-regulation rooms will not work. For example, Wiglesworth and Farnworth (2016) looked at the use of sensory rooms as part of the therapeutic offerings within a forensic mental health setting, and Kopec and Harte (2019) explored the use of de-escalation rooms as part of a trauma-informed design for high-risk middle schoolers. The fundamental premise of special rooms is to provide a safe and private space to weep, scream, or to become physical. The idea is to allow the individual a place to work through their emotions.

Like other symptoms, depression and suicidality have not been discussed in the literature in terms of the designed environment as a facilitator or mitigator. The assumption to mitigate suicidal behaviours would be to use the designed environment to increase steps in the process and to increase the amount of time between thought and action. More time and more steps provide greater 
opportunities to reconsider or for a loved one to intervene. Depression, an emotion that is often a precursor to suicide, has some evidence related to light. Full-spectrum sunlight has been shown to have an effect with serotonin which is a mood elevator, and any light has been shown to influence levels of melatonin which relates to the sleep-wake cycle (Kopec, 2018). In theory, access to full-spectrum sunlight combined with a stable routine of light brightening and dimming would help increase serotonin and regulate melatonin levels, thereby helping to address depression.

\section{Design strategies}

The Americans with Disabilities Act (ADA) was enacted by George H.W. Bush on July 26, 1990. This was a historical benchmark and milestone that demonstrated the United States' commitment to full and equal opportunity for all citizens (ADA National Network, 2019). The ADA was an important first step toward inclusiveness of people with differing abilities to use public spaces. There are four different regulations contained within the ADA; title I is employment, title II is state and local government, title III is public accommodations, and title IV is telecommunications. The latest revisions and updates made to title III provides further clarification of public accommodations to include an obligation for appropriate provisions for auxiliary aids and services for people with disabilities. The ADA is regarded as only a baseline for inclusive measures and should be expanded upon as part of a professional's practice. Of the design strategies, the ADA is the only strategy mandated by law within the United States.

Universal design is a concept based on a belief that to the greatest extent possible all designs should be usable by all people, all the time, and without the need for adaptation or specialized design (Mace, 2019). Ronald Mace is referred to as a pioneer for accessible design within the United States and was instrumental in the passage of national legislation prohibiting discrimination against people with disabilities, including the Fair Housing Amendments Act and the Americans with Disabilities Act. Universal design is meant to simplify life by designing the built environment to be usable by everyone regardless of ability. There are seven principles of universal design that act as guidelines for design; equitable use, flexibility in use, simple and intuitive use, perceptible information, tolerance for error, low physical effort, and size and space for approach and use (Centre for Excellence in Universal Design, 2014).

Aging in place is another design philosophy. This method of design pertains to residential design and is based on the idea that a 
person should be able to grow old in their home, or other familiar surroundings for as long as possible and without compromise to their quality of life (National Institutes of Health, 2017). Jernigan et al. (2015) states that a team of designers from Gensler identified the four major themes that design should follow for an actively aging population. These four themes include connectivity, choice, independence, and wellness. Jernigan et al. (2015) further states that connectivity is the ability to maintain relationships, choice is about living in a location that fits the needs and preferences of the occupant, independence is the ability care for oneself without assistance, and wellness is about managing illnesses and maintaining health. The four major themes of aging in place, in addition to the seven principles of universal design, and the mandates under the Americans with Disabilities Act are resources that can be used when developing designs for public environments or mass-produced housing.

Human-centred design is the latest in codified design strategies. It has been born of the WELL Building Standards adopted by the United States Green Building Council (USGBC) in October 2014. WELL is managed and administered by the International WELL Building Institute (IWBI), a public benefit corporation whose mission is to improve human health and wellbeing through the built environment (Knox, 2015). Each of the design strategies that make up the WELL Building Standard is an evolutionary branch from the prior guidelines. The common denominator from each of these branches, however, is that design is completed in absence of a person. The basis for design concepts is from a high level of probabilities with broad-based approaches for accommodation. This approach works well when the end user is unknown such as the case of public buildings or, in the case of aging in place, when a developer acquires large swaths of land for replicated housing.

Person-centred design differs from the above design philosophies because it is based on the design needs of an individual. Instead of working from the high level of human-centred design and adapting those designs for the person, person-centred designs are developed for the individual and builds from common identifiable factors to determine best outcomes. The position of this study is that designs for a person with a specific health condition should be based on person-centred designs because the outcomes will be more reliable. Once the affected individual's needs have been met, then consideration for other families should ensue. 


\section{Method}

Methodological reductionism is a method used to handle identified symptoms obtained from the literature pertaining to CTE. Once symptoms of CTE were identified, they became factors of analysis. Each symptom was assessed for its relationship to the design environment. CTE symptoms were stratified according to behavioural or physical manifestations (see Table 1 and Table 2) and assessed through additional data obtained from the literature for environmental causality, mitigation, or accommodation. These outcomes were then included in a chart as a design implication which was assessed for relationships to specific design actions.

\begin{tabular}{|c|c|c|c|}
\hline \multirow{7}{*}{$\begin{array}{r}\text { Table } 1 \\
\text { Behavioural } \\
\text { analysis }\end{array}$} & Symptom & Implication & Design Measures \\
\hline & Paranoia & Fear of unknown & $\begin{array}{l}\text { - Increase visual access } \\
\text { throughout all spaces }\end{array}$ \\
\hline & $\begin{array}{l}\text { Anger/ } \\
\text { aggression }\end{array}$ & $\begin{array}{l}\text { Hitting, throwing, } \\
\text { threatening }\end{array}$ & $\begin{array}{l}\text { - Specify tempered glass or } \\
\text { thick plexiglass to minimize the } \\
\text { production of shards } \\
\text { - Avoid the use of accessories that } \\
\text { can be easily lifted and tossed. } \\
\text { - Increase process ordering for } \\
\text { places were dangerous objects } \\
\text { are stored (i.e. knives) }\end{array}$ \\
\hline & Depression & $\begin{array}{l}\text { Lighting, activity, } \\
\text { contemplation }\end{array}$ & $\begin{array}{l}\text { - Access to full spectrum light } \\
\text { - Access to cardiovascular } \\
\text { activities } \\
\text { - Access to quiet private spaces }\end{array}$ \\
\hline & Apathy & $\begin{array}{l}\text { Lighting, activity, future } \\
\text { orientation }\end{array}$ & $\begin{array}{l}\text { - Access to full spectrum light } \\
\text { - Access to cardiovascular } \\
\text { activities } \\
\text { - Space for gardening or similar } \\
\text { hobbies }\end{array}$ \\
\hline & Suicidality & $\begin{array}{l}\text { Process ordering, future } \\
\text { orientation, visuals of } \\
\text { support }\end{array}$ & $\begin{array}{l}\text { - Several steps to acquire life } \\
\text { threatening items } \\
\text { - Space for gardening or similar } \\
\text { hobbies } \\
\text { - Images of loved ones mounted } \\
\text { to wall (not just hung) }\end{array}$ \\
\hline & $\begin{array}{l}\text { Impulsive/ } \\
\text { reaction }\end{array}$ & $\begin{array}{l}\text { Evoke theta waves for } \\
\text { calming }\end{array}$ & $\begin{array}{l}\text { - Provide rhythmic organic shapes } \\
\text { and movement } \\
\text { - Include rhythmic sounds }\end{array}$ \\
\hline
\end{tabular}

Once the relationships between symptoms and design elements were identified, this provided another set of factors from which to base design initiatives. Factors were assessed using design thinking as a methodology. The use of design thinking as a methodology is context dependent, thereby making it more human-centred (Leifer \& Meinel, 2016). The process of design thinking in Leifer and Meinel's 
model (2016) has three factors: human, technical, and context. This study identified design factors in relation to the effect of the condition on the human body (symptoms). With this approach, ideations were identified in singularity as prototypes and then aggregated into a single design motif.

\begin{tabular}{|c|c|c|}
\hline Symptom & Implication & Design Measures \\
\hline $\begin{array}{l}\text { Spatial } \\
\text { awareness }\end{array}$ & Bumping into objects & $\begin{array}{l}\text { - Bullnose counter and tabletops } \\
\text { - Round out corners } \\
\text { - Use windows and glass doors } \\
\text { with muntins to increase visual } \\
\text { detection }\end{array}$ \\
\hline $\begin{array}{l}\text { Reduced } \\
\text { cognition }\end{array}$ & $\begin{array}{l}\text { Subject to optical } \\
\text { illusions }\end{array}$ & $\begin{array}{l}\text { - Avoid contrasting } \\
\text { complimentary colours } \\
\text { - Avoid repeating or contrasting } \\
\text { patterns } \\
\text { - Allow only diffused lighting into } \\
\text { spaces } \\
\text { - Avoid velvets and similar } \\
\text { materials that can appear in } \\
\text { different ways }\end{array}$ \\
\hline Headaches & $\begin{array}{l}\text { Lighting, noise, and } \\
\text { strong aromas }\end{array}$ & $\begin{array}{l}\text { - Decrease lighting in the } \\
\text { afternoon and evening } \\
\text { - Decrease use of materials with a } \\
\text { reflective surface } \\
\text { - Provide dimly lit cooler } \\
\text { environments with noise controls } \\
\text { - Install quiet direct exhaust fans } \\
\text { to remove cooking smells }\end{array}$ \\
\hline $\begin{array}{l}\text { Declined } \\
\text { responsiveness }\end{array}$ & Visual cues & $\begin{array}{l}\text { - Keep all purpose fire } \\
\text { extinguishers in plain sight of } \\
\text { where a fire could break out }\end{array}$ \\
\hline Memory loss & $\begin{array}{l}\text { Use of implicit or cluster- } \\
\text { based ordering }\end{array}$ & $\begin{array}{l}\text { - Cluster cabinetry using macro } \\
\text { clues such as colour or placement } \\
\text { - Use process ordering } \\
\text { arrangements }\end{array}$ \\
\hline $\begin{array}{l}\text { Reduced } \\
\text { attentional } \\
\text { capacity }\end{array}$ & $\begin{array}{l}\text { Allow for multiple and } \\
\text { diverse activities through } \\
\text { greater segmentation }\end{array}$ & $\begin{array}{l}\text { - Provide diverse spaces that allow } \\
\text { for unique activities }\end{array}$ \\
\hline
\end{tabular}

Table 2

Physical analysis

\section{Residential Design for CTE}

\section{Design measures}

Understanding the design implications for the different symptoms associated with CTE allowed for the exploration of specific design initiatives. The master bedroom on the northeast portion of the home, for example, was done because headaches and depression were identified as common symptoms of CTE. This placement would 
thus allow for morning sunlight to penetrate the room and help the person wake up by facilitating the reuptake of melatonin (see Figure 1). This placement would concurrently allow the room to be darker and cooler during the mid and late afternoon when the sun moves westward, and when headaches are more likely to present.

Figure 1 Residential floor plan (NTS) (Image by authors)

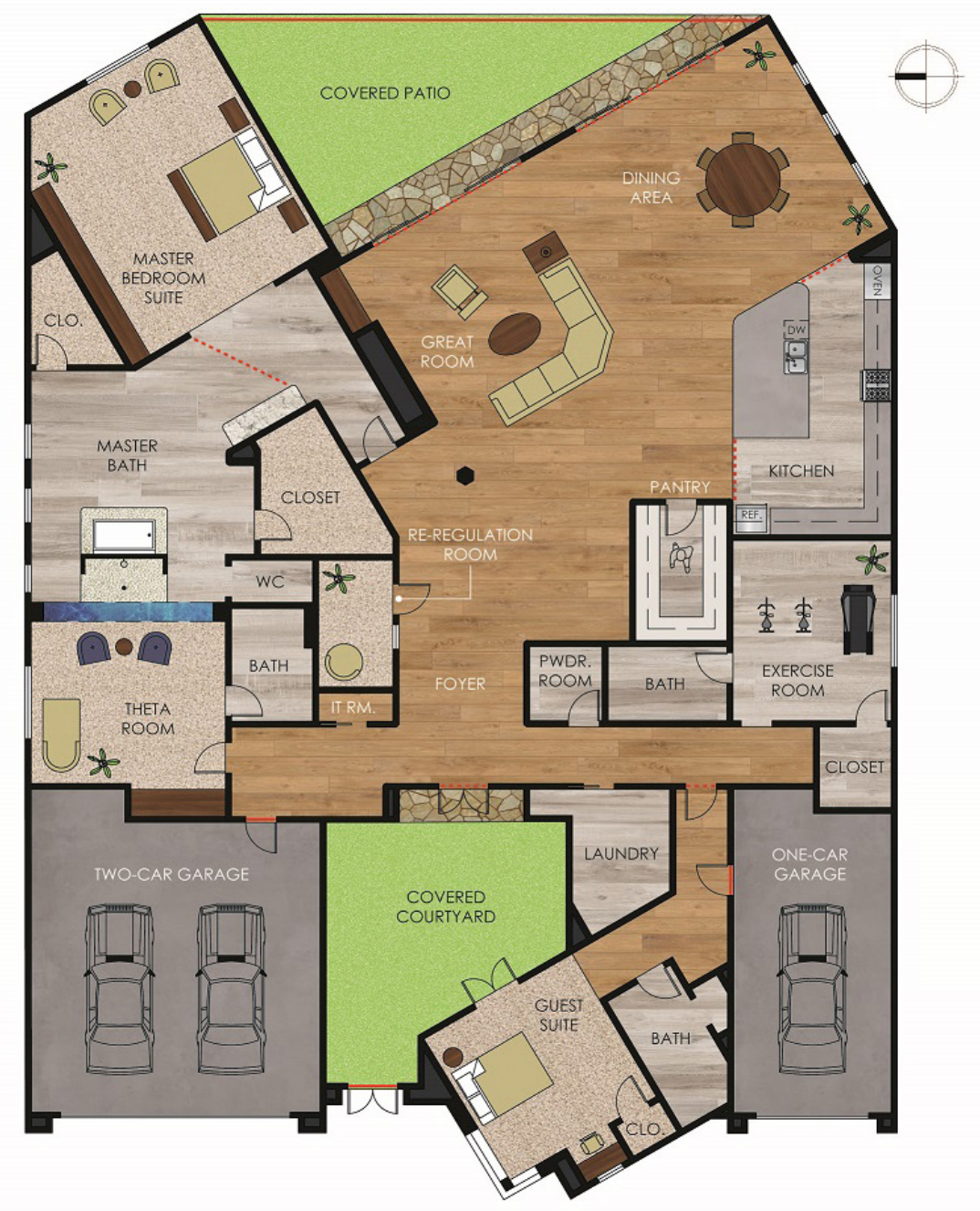

The onset of headaches also come from flickering lights and the accidental creation of illusions caused by design initiatives. The presence of flickering light can come from the actual lighting or from reflections on highly polished surfaces. To help with lighting controls, matte finishes were used for all surfaces. To prevent direct sunlight from streaming into the home, awnings and trees were used to provide shade to the exterior of the home, and interior shades and window decals were placed on some of the windows to control the light from penetrating the interior spaces. To prevent the potential for illusions, a softer colour palette was selected, and bright, heavily saturated colours were avoided. 
Other common symptoms associated with CTE are irritability, impulsivity, and explosivity. According to the frustration-aggression hypothesis, when a desired act, such as not being able to lift a shade, becomes impeded, the person will start to feel frustrated. This frustration turns into aggression, such as pulling the shade out of the wall. Displacement often follows when a caregiver or loved one is spoken to as if the shade not rising was their fault. Hence, an analysis of probable triggers for irritability, impulsivity, and explosivity had to be considered throughout the design development stage. Additionally, a re-regulation/de-escalation room was added to the space as a way to constructively address undesirable emotions. The inclusion and subsequent beneficial uses of this room, however, requires sets of rules to be established and followed. Because of these added social layers, the inclusion of a re-regulation/de-escalation space must be carefully considered.

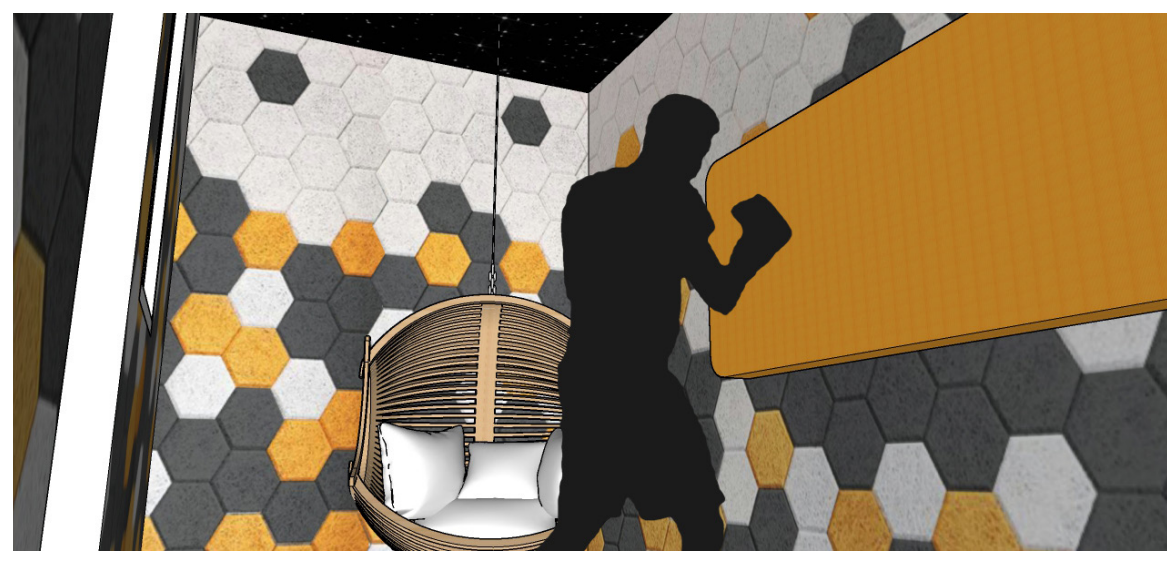

The re-regulation/de-escalation room (see Figure 2) in this design is only meant to demonstrate what a re-regulation/de-escalation space might look like. This one includes acoustical tile so that a person can yell and scream without disruption to others, a dense foam pad mounted onto the wall so that a person can punch the wall and relieve his or her frustration or irritability without harm to him or herself, or the home. Also, a wide swinging chair was included to facilitate rocking while weeping. This small room is meant to be the affected person's private space where he or she can constructively process the intensity of emotion they experience.

Limited attention spans and depression are two symptoms common to people affected by CTE. Serotonin is a mood enhancer that can be positively affected by exposure to full-spectrum sunlight offered by a covered outdoor patio without being in the direct sun. The idea is to provide outdoor areas where the person can enjoy undirected restorative attention while concurrently helping to increase serotonin. Additionally, an exercise room (see Figure 3) was
Figure 2

Re-regulation/deescalation room (Image by authors) 
included in this design because cardiovascular activity helps with depression through the release of endorphins. To help keep the activities interesting, we included a large concave video screen that allows the person to select from a variety of simulated experiences that include walking/running, riding a bicycle, or cross-country skiing through a variety of nature scenes.

The exercise room accomplishes two things. The first is access through a variety of nature scenes and based on the attention restoration theory might help with the person's concentration levels. To help bolster the experiential qualities, the wall and screen are concave to include the scene in the person's peripheral sight. While this is an example, other design features can be explored to accommodate similar outcomes.

Figure 3

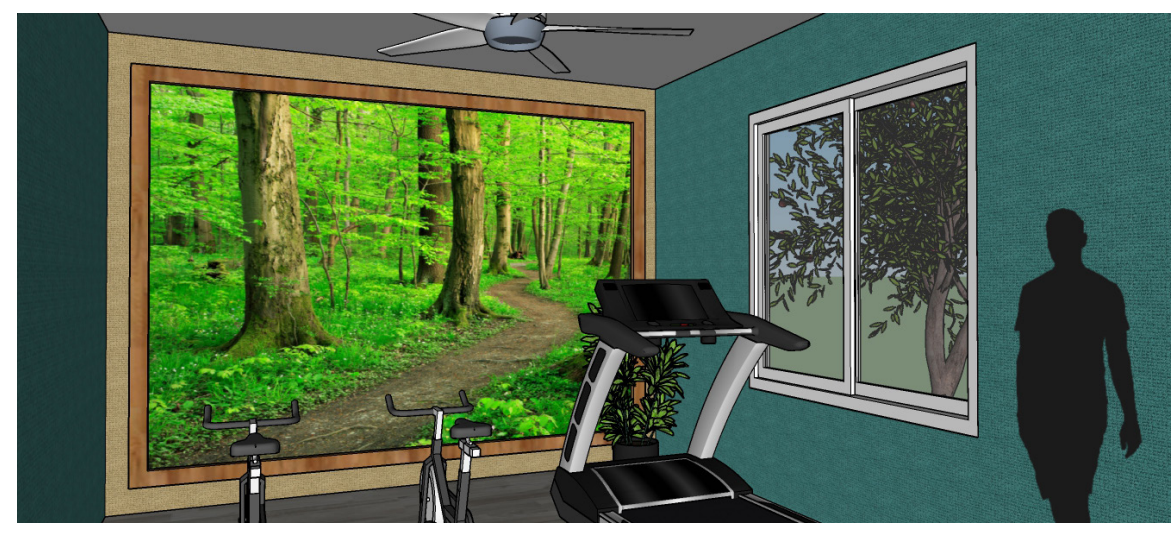

Safe and private spaces such as the re-regulation/de-escalation room allow for active processing of exaggerated and displaced behaviours. The exercise space allows for a variety of natureinspired scenery while one exercises. The restoration qualities of this space also help with the release of neurochemicals known to elevate mood. These two spaces in combination to outdoor seating allow for access to the full-spectrum sunlight which helps with the production of the mood-stabilising neurotransmitter serotonin. The final space that we included for this study is called the Theta Room (see Figure 4).

Designed to be a quiet contemplative area for self-disclosure through journaling, speaking with another, or just to meditate, the primary purpose of this space is to induce theta waves as a way to help assist with memory and to provide a preventative or an afterthe-fact way to process events and actions. The Theta Room has a wavy wall surface to help reduce the rectilinear effects, and it also has a large aquarium. The air pump that releases bubbles in the water as part of oxygenation provide white noise to drown out competing sounds. The addition of the wavy wall helps to lessen 
sound reverberation, and the moving bubbles and fish provide rhythmic movements that help to relax the mind and induce theta waves.

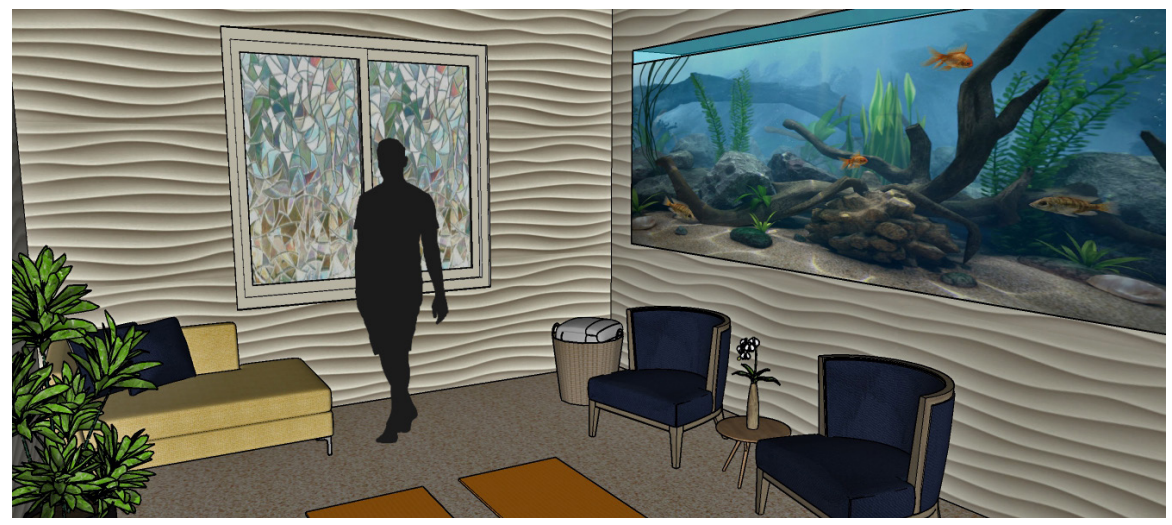

The identified prototypes are based on the generation of designs built upon specific symptoms obtained from reduction methods and then applied via design thinking. To determine the veracity of these design prototypes, they will need to be constructed then measured for their effectiveness for a person with CTE.

\section{Conclusion}

Person-centred design has long been the domain of clinical health practitioners. However, clinical health practitioners often lack design skills that meet a specific need without highlighting a person's differing abilities. This exploratory study used a reductionist methodology applied to the literature pertaining to the health condition of CTE. Through the process of reductionism, specific symptoms that often accompany CTE were revealed. Individual symptoms were then assessed through a second reductionist approach. This secondary tier of analysis was based on environmental relationships that facilitated, lessened, or prevented the appearance of the subject symptom. These levels of analysis extend the practice by providing probable solutions to specific health symptoms, thereby including designers into the overall healthcare team.

By identifying specific factors from a reductionist approach, followed by a design thinking methodology, we then were able to better empathise and brainstorm probable design outcomes for specific needs that may be required for a person affected by CTE. Through our process, we were able to fully develop three spaces within a residential setting that address symptoms common to people affected with CTE.
Figure 4

Theta room

(Image by authors) 
The strength of these designs is that they do not call attention to a differing ability, and even the re-regulation or de-escalation room could be reconceptualised as a fun getaway space. While there is a high probability that all, or some, of the elements within these design prototypes will be effective, further research will need to be done to determine overall efficacy. However, given the complexity of the designed environment, further research should be limited to the capacity of specific rooms satisfying the specific aspect of the health condition. Further research will also need to examine the integration of needs between competing and complementary outcomes such as spatial limitations, budget constraints, and the needs of cohabitants.

\section{References}

ADA National Network. (2019). ADA: Findings, purpose, and history. Retrieved from https://www.adaanniversary.org/findings_ purpose

American Academy of Orthopedic Surgeons. (2014, March 14). Significant head, neck injury risk associated with extreme sports. ScienceDaily. Retrieved from www.sciencedaily. com/releases/2014/03/140314093733.htm

American Speech, Language, and Hearing Association (n.d.). Traumatic Brain Injuries in Adults. Retrieved from www.asha.org/PRPSpecificTopic. aspx?folderid=8589935337\&section=Incidence_and_ Prevalence

Blennow, K., Brody, D. L., Kochanek, P. M., Levin, H., McKee, A., Ribbers, G. M., Yaffe, K., \& Zetterberg, H. (2016). Traumatic brain injuries. Nature Reviews Disease Primers 2, 16084. https://doi.org/10.1038/nrdp.2016.84

Centre for Excellence in Universal Design (2014). The 7 Principles. Retrieved from http://universaldesign.ie/What-isUniversal-Design/The-7-Principles/\#p1

Deng, H., Yue, J. K., Winkler, E. A., Dhall, S. S., Manley, G. T., \& Tarapore, P. E. (2019). Adult firearm-related traumatic brain injury in United States trauma centers. Journal of Neurotrauma, 36(2), 322-337. https://doi.org/10.1089/neu.2017.5591

Dewan, M. C., Rattani, A., Gupta, S., Baticulon, R. E., Hung, Y. C., Punchak, M., Agrawal, A., Adeleye, A. O., Shrime, M. G., Rubiano, A. M., Rosenfeld, J. V., \& Park, K. B. (2018). 
Estimating the global incidence of traumatic brain injury. Journal of Neurosurgery, 130(4), 1039-1408.

Deziel, C. (2018, April 23). Which colors reflect more light? Sciencing. Retrieved from: https://sciencing.com/colors-reflectlight-8398645.html.

Filer, W., \& Harris, M. (2015). Falls and traumatic brain injury among older adults. North Carolina Medical Journal, 76(2), 111-114. https://doi.org/10.18043/ncm.76.2.111

Friedman, D.I., \& De Ver Dye, T. (2009). Migraine and the environment. Headache: Journal of Head and Face Pain, 49(6), 941-952. https://doi.org/10.1111/j.1526-4610.2009.01443.x

Harvey, L. (2012). Social research glossary. Retrieved from https:// www.qualityresearchinternational.com/socialresearch/ positivism.htm.

Jernigan, R., Johnston, C., McAlister, B., \& Lin, H. (2015). Design for active aging. Gensler Research Institute: Research \& Insight. Retrieved from https://www.gensler.com/research-insight/ gensler-research-institute/design-for-active-aging

Kaplan, R., \& Kaplan, S. (1989). The experience of nature:A psychological perspective. Cambridge, England: Cambridge University Press.

Knox, N. (2015). What is WELL? Retrieved from https://www.usgbc. org/articles/what-well

Kopec, D. (2018). Environmental psychology for design (3rd ed.). New York: Bloomsbury Press.

Kopec, D., \& Harte, J. D. (2019). Design as the missing variable in trauma-informed schools. In R. Rosen (Ed.), Supporting and educating traumatized students: A guide for school-based professionals (2nd ed.). Oxford: Oxford University Press.

Leifer, L., \& Meinel, C. M. (2016). Design thinking becomes foundational. In H. Plattner, C. Meinel, \& L. Leifer (Eds.), Design thinking research: Making design thinking foundational (pp. 1-4). New York: Springer.

Li, D., and Sullivan, W.C. (2016). Impact of views to school landscapes on recovery from stress and mental fatigue. Landscape and Urban Panning, 148, 149-158. https://doi.org/10.1016/j. landurbplan.2015.12.015 
Mace, R. (2019). What is "Universal Design?" Retrieved from https:// universaldesign.org/definition

McKee, A. C., Stein, T. D., Kiernan, P. T., \& Alvarez, V. E. (2015). The neuropathology of chronic traumatic encephalopathy. Brain Pathology, 25(3), 350-364. https://doi.org/10.1016/ B978-0-444-63954-7.00028-8

National Institutes of Health: National Institute of Aging (2017, May 1). Aging in place: Growing older at home. Retrieved from: https://www.nia.nih.gov/health/aging-place-growingolder-home

Ohly, H., White, M. P., Wheeler, B. W., Bethel, A., Ukoumunne, O. C., Nikolaou, V., \& Garside, R. (2016). Attention Restoration Theory: A systematic review of the attention restoration potential of exposure to natural environments. Journal of Toxicology and Environmental Health, Part B, 19(7), 305-343. https://doi.org/10.1080/10937404.2016.1196155

Patel, D., Sharma, K., Chauhan, C. S., Jadon, G., \& Diwaker, A. (2013). An Overview - Chronic traumatic encephalopathy (CTE). International Journal of Advanced Research in Pharmaceuticals and Bio Sciences, 3(3), 73-83.

Reed-Guy, L. (2018, April 9). Head injury. Retrieved from: https:// www.healthline.com/health/head-injury

Reiner, M., Rozengurt, R., \& Barnea, A. (2014). Better than sleep: Theta neurofeedback training accelerates memory consolidation. Biological Psychology, 95, 45-53. https://10.1016/j. biopsycho.2013.10.010

Risdall, J. E., \& Menon, D. K. (2011). Traumatic brain injury. Philosophical Transactions of the Royal Society B: Biological Sciences, 366(1562), 241-250. https://doi.org/10.1098/rstb.2010.0230

Sánchez-Tena, M. A., Alvarez-Peregrina C., Valbuena-Iglesias M. C., \& Palomera, P. R. (2018). Optical illusions and spatial disorientation in aviation pilots. Journal of Medical Systems, 42(5), 79. 10.1007/s10916-018-0935-4

Smith, D. H., Johnson, V. E., Trojanowski, J. Q., \& Stewart, W. (2019). Chronic traumatic encephalopathy: Confusion and controversies. Nature Reviews Neurology, 15, 179-183. https://doi.org/10.1038/s41582-018-0114-8

Taylor, A. F., \& Kuo, F. E. M. (2011). Could exposure to everyday green spaces help treat ADHD? Evidence from children's play 
settings. Applied Psychology: Health Well-Being, 3(3), 281303. https://doi.org/10.1111/j.1758-0854.2011.01052.x

Turner, R. C., Lucke-Wold, B. P., Robson, M. J., Lee, J. M., \& Bailes, J. E. (2016). Alzheimer's disease and chronic traumatic encephalopathy: distinct but possibly overlapping disease entities. Brain Injury, 30(11), 1279-1292. https://doi.org/10.10 80/02699052.2016.1193631

Vynorius, K. C., Paquin, A. M., \& Seichepine, D. R. (2016). Lifetime multiple mild traumatic brain injuries are associated with cognitive and mood symptoms in young healthy college students. Frontiers in Neurology, 7(3), 188. https:// 10.3389/ fneur.2016.00188

Wiglesworth, S., \& Farnworth, L. (2016). An exploration of the use of a sensory room in a forensic mental health setting: Staff and patient perspectives. Occupational Therapy and Criminal Justice, 23(3), 255-264. https://doi.org/10.1002/oti.1428

Williams, J. D., \& Gruzelier, J. H. (2001). Differentiation of hypnosis and relaxation by analysis of narrow band theta and alpha frequencies. International Journal of Clinical and Experimental Hypnosis, 49(3), 185-206. https://doi. org/10.1080/00207140108410070

Zetterberg, H., Winblad, B., Bernick. C., Yaffe, K., Majdan, M., Johansson, G., Newcombe, V., Nyberg, L., Sharp, D., Tenovuo, O., \& Blennow, K. (2019). Head trauma in sports: Clinical characteristics, epidemiology and biomarkers. Journal of Internal Medicine, 285(6), 624-634. https://doi. org/10.1111/joim.12863 
Dak Kopec, Kendall Marsh 